\title{
MJN IMPLEMENTING OF AN EDUCATIONAL PROGRAM ON PATIENTS' KNOWLEDGE AND SELF-EFFICACY REGARDING RECURRENT CEREBROVASCULAR STROKE
}

\author{
Mohamed G. Elbqry ${ }^{1 *}$, Wafaa I. Sherif ${ }^{2}$, Naglaa E Mahdy ${ }^{3}$, Samia H Gaballah ${ }^{1}$, Ashraf M. \\ Altantawy ${ }^{4}$
}

${ }^{1}$ Department of Medical Surgical Nursing, Faculty of Nursing, Suez Canal University, Egypt ${ }^{2}$ Department of Medical Surgical Nursing, Faculty of Nursing, Mansoura University, Egypt

${ }^{3}$ Department of Medical Surgical Nursing, Faculty of Nursing, Ain Shams University, Egypt

${ }^{4}$ Psychiatric and Neurological Diseases, Faculty of Medicine, Suez Canal University, Egypt

*Corresponding Author's Email: mohamedgoda@nursing.suez.edu.eg

\begin{abstract}
Cerebrovascular stroke "CVS", also known as "brain attack": is an umbrella term of the common, crippling, and a deadly serious neurologic disease that causes a sudden loss of brain function. Recurrent CVS declared as an individual's history of a previous CVS, can be prevented through effective adherence with therapeutic regimen to enhance individual's self-efficacy. Aim: the aim was to evaluate effect of educational program on knowledge and self-efficacy among patients with recurrent cerebrovascular stroke. Methodology: Setting: The study was conducted at Neuropsychiatry Department at Suez Canal University Hospitals. Design: A quasi-experimental research design was used (one group pre post-test). Subject: A purposive sample of eighty-four adult patients with recurrent cerebrovascular stroke was chosen. Tools: Assessment questionnaire was used to assess the patient's demographic characteristics, medical history and interview questionnaire to assess the patients' level of knowledge regarding cerebrovascular stroke, stroke self-efficacy questionnaire to assess the strength of an individual's belief in their individual ability to respond difficult or new situations was used. Result: There was positive significant correlation between the studied patient's level of knowledge at the pre, post and follow-up phase of the study. Also, there was positive significant correlation between the studied patient's stroke selfefficacy score at the pre, post and follow-up phase of the study. Conclusion: Effective implementation of educational program on the studied patients' is necessary to increase the level of knowledge and self-efficacy among patients with recurrent cerebrovascular stroke. Recommendation: Establishing recurrent cerebrovascular stroke's counseling with specialized professional teams is necessary to provide knowledge regarding recurrent cerebrovascular stroke and how to improve patients' self-efficacy.
\end{abstract}

Keywords: Recurrent Cerebrovascular Stroke, Patient's Knowledge, Self-efficacy

\section{INTRODUCTION}

Cerebrovascular stroke "CVS", also known as "brain attack", is an umbrella term of the common, crippling, and a deadly serious neurological disease that causes a sudden loss of brain function followed by the neurological deficits. Recurrent cerebrovascular stroke is declared as an individual with a history of a previous cerebrovascular stroke, registered with a new stroke event (Lau, Pendlebury \& Rothwel, 2018).

Epidemiological study around the world suggest that cerebrovascular stroke is the second driving reason for death among individuals over the age of 60 , and the fifth driving reason for death in individuals at 15 to 59 years of age group. Regardless of $80 \%$ of recurrent cerebrovascular stroke every year around 700,000 individuals encounter another or repetitive stroke (Mahdy et al., 2016).

Benjamin et al., (2018), stated that, stroke happens almost 152,000 times each year and additionally it is the fourth driving reasons for death in the United Kingdom; that is one at regular intervals, there are around 1.2 million stroke survivors in the United Kingdom. From those, 3 will suffer repetitive cerebrovascular stroke or 
transient ischemic attack. The most burden hazard probability of intermittent stroke is in the early month. Cerebrovascular stroke in Egypt achieved $14.37 \%$ of total death, positioning Egypt as the most elevated incidence of the handicaps due to cerebrovascular stroke recurrence; occurrence rate in Upper Egypt was 18\%.

The prevalence rate of ischemic stroke was significantly higher than that of hemorrhagic stroke; illiterate participants had a significantly higher prevalence rate than those who were literate. There was no significant difference in the prevalence rate between rural and urban areas or between males and females. More than half of the participant in the study had one or more risk factors with hypertension being the most common followed by diabetes mellitus (Khedr et al., 2014).

As recurrent cerebrovascular attack is a complex disease, about $80 \%$ of cerebrovascular stroke can be prevented. It needs the efforts and practice of the multidisciplinary team. Among them are nurses who play a crucial role in all phases of stoke care to enhance patients' outcomes, decrease time of hospital stay, and decrease hospital costs and possible complications. Nurses serve as an educator for the patient about the knowledge of disease towards both the patient and their family members. They support and encourage health behavior for the active participation in all aspects of selfcare for better outcomes and health promotion. Patient education in nursing practice regarding adherence to the therapeutic regimen is essential for better outcomes (Lewis et al., 2016; WHO, 2019).

\section{Significance of the study}

At Suez Canal and Sinai area: The incidence and prevalence of recurrent cerebrovascular stroke in Suez Canal University hospitals have been recognized increasingly during the last decade mainly at the neuropsychiatric department. This was found not only among elderly people, or diabetic patients, but even among individuals with or without hypertension (Elbqry et al., 2017).

Consequently, at national level, in Egypt; there were high incidence and prevalence, the mean and median crude prevalence rates across the five studies, which were conducted in southern Egypt showed $721 \%$ and $6.55 \%$ respectively. While the mean and median crude incidence rates were $1.87 \%$ and $1.80 \%$ cerebrovascular stroke accounted for about 1 of every 19 deaths in the United States, individuals died of stroke every 3 minutes 42 seconds (Abd-Allah et al., 2018).
At international level; approximately $3 \%$ of males and $2 \%$ of females reported that they were disabled because of stroke. There were 5.5 million deaths attributed to cerebrovascular disease worldwide (2.7 million deaths from ischemic stroke and 2.8 million deaths from hemorrhagic stroke). According to 2016 data, Eastern Europe, East Asia, and parts of Southeast Asia, Central Asia, and sub-Saharan Africa had the highest rates of stroke mortality (Urden et al., 2017; Kim etal., 2018).

\section{METHODOLOGY}

The aim of the present study was to evaluate effect of educational program on knowledge and self-efficacy among patients with recurrent cerebrovascular stroke.

The following research hypotheses were formulated to fulfill the aim of this study:

H1: Significant correlation between the studied patients' level of knowledge at the study phases.

$\mathrm{H} 2$ : Significant correlation in self-efficacy scores among the studied patients.

\section{Research Design}

A quasi experimental research design (one intervention group, assign nonrandom), was used in the current study, pre-, immediate post implementing and follow up was done at two months post educational program implementation.

\section{Setting}

This study was conducted in Suez Canal University hospitals at Neuropsychiatric department.

\section{Subjects}

A purposive sample of 84 cases (50 males and 34 females) participated in the current study at the time of hospitalization.

The sample calculated were based upon prevalence of adherence to therapeutic regimen which is $60 \pm 5 \%$ (Kamal et al., 2015; Elbqry et al., 2017), equation is:

Sample size $n=\left[\mathrm{DEFF}^{*} \mathrm{~Np}(\mathrm{l}-\mathrm{p})\right] /\left[\left(\mathrm{d}^{2} / \mathrm{Z}^{2}{ }_{1-\alpha / 2}{ }^{*}(\mathrm{~N}-\mathrm{l})+\mathrm{p}^{*}(\mathrm{l}-\mathrm{p})\right]\right.$

Results from OpenEpi, Version 2, open source calculator--SSPropor 
The estimated sample size is made at assumption of $95 \%$ confidence level and $80 \%$ power of study.

Any hospitalized patient with recurrent cerebrovascular stroke in the study setting during the period of the study implementation and being eligible for the following inclusive criteria:

\section{Inclusive criteria}

Adult patients more than or equal to 20 years of age of both sexes, with recurrent cerebrovascular stroke and who did not receive any educational program previously or any other guidelines about adherence with therapeutic regimens of recurrent cerebrovascular stroke.

\section{Exclusive criteria}

Patient who are unconscious, disoriented or/ and aphasic.

\section{Tools for data collection}

Tool I, Assessment questionnaire: it was developed by the researcher based on the related literature and filled from patients' files, to assess the studied patients' sociodemographic characteristics, medical history before and immediately post two months of program implementation phases (Lewis et al., 2016). The questionnaire consisted of three parts:

Part 1: was used to assess the studied patients' socio-demographic characteristics, such as; age, gender, occupation, marital status, level of education, monthly income, body mass index, accompanying persons at home and place of residence.

Part 2: was used to assess the studied patients' present medical history (at the time of admission, type \& causes of recent cerebrovascular stroke, frequency of stroke, laboratory, non-laboratory diagnostic studies and medical management).

Part 3: was used to assess past medical history (at the time of previous stroke, type and causes of previous stroke and patients' family history).

\section{Scoring system of body mass index}

The total score had been calculated as:

Very thin. If total $\mathrm{BMI} \leq 20 \%$

Normally. If total $\mathrm{BMI} \geq 20 \%: 25$.

Obeys. If total $\mathrm{BMI} \geq 26 \%: 30 \%$.

Very obeys. If total $\mathrm{BMI} \geq 31 \%$.
Tool II, Patients' structured interview questionnaire: This was developed by the researcher based on the related literature and filled from patients at the time of interview before program implementation, immediately post program implementation and post two months of program implementation (Martino, 2016; Hinkle et al., 2017). It included 25 questions as true or false and multiple-choice questions, to assess the patients' level of knowledge regarding cerebrovascular stroke.

Scoring system: it was considered as the following (Cabral etal., 2015):

- $\geq 60 \%$ was considered a satisfactory level of knowledge, when the total grades were $\geq 15$ grades.

- $\quad<60 \%$ was considered as unsatisfactory level of knowledge, when the total grades were $<15$ grades.

Tool III, Stroke Self-Efficacy Questionnaire (SSEQ): it is one of the first measures of self-efficacy designed specifically for stroke patients at the time of interview pre intervention immediately and post two months of program implementation. Cronbach Alpha reliability coefficient for the 13-item SSEQ was 0.90, which suggests high internal consistency (Bland \& Altman 1997).

\section{Scoring system}

The scoring system was adopted from Jones, Partridge \& Reid, (2008), by the researcher: items were rated on a likert scale from 1 to 10 , as from $0: 3=$ weak selfefficacy (totally 13-50 grades), from 4:7=good selfefficacy (totally 51-100 grades) and finally 8:10=stronger self-efficacy (totally101-130 grades).

\section{Testing validity}

This stage was developed by seven experts from different academic categories (professor, assistant professor and senior lecturer) of Medical Surgical Nursing as well as four Neuropsychiatric medicine from Suez Canal University and three from Ain Shams University.

\section{Content reliability}

Coefficient of reliability of the evaluating tools II (knowledge about stroke and its recurrence) was measured by Cronbach's $\alpha$ alpha. The reliability scores as above were 0.863 . This Indicate high internal consistency of the used tools. Coefficient of reliability 
of the evaluating tools III for the 13 -item questions was 0.90, which suggests high internal consistency.

\section{Pilot study}

It was conducted on $10 \%$ of the subjects to test whether tools of data collection are clear, understandable, feasible and valid. After piloting it, modification of the study tools was done including addition or omissions.

\section{Field work}

Data collection of this study was carried out in the period from October 2017 to March 2018, through the following phases:

\section{Assessment Phase (Pretest)}

In this stage, the researcher assessed the actual educational needs by using pre-constructed tools; the researcher interviewed each patient throughout using (Tool I, Tool II \& Tool III), at morning, afternoon and night shift.

\section{Planning phase}

The researcher developed the educational program using the baseline information gathered in the assessment phase. This educational program study aimed to evaluate effect of educational program on knowledge and selfefficacy among patients with recurrent cerebrovascular stroke. The educational program included materials to improve patients' knowledge regarding the definition of cerebrovascular stroke recurrence. This included clinical manifestations, predisposing factors, investigations and treatment, in addition to its role to measure and improve patient's self-efficacy.

\section{Implementation phase}

The implementation of the educational program was carried out at neuropsychiatric department as the study setting. The educational program was administered in three sessions from December 2017 to May 2018; the duration of each session was for 10 to 35 minutes. The sample was divided into small groups; each session of the educational program implementation included at least two patients. At the beginning of the first session of the educational program, patients were given an idea regarding program objectives, contents, and procedures.
The educational program was presented in a clear and concise form, following the principles of adult learning, focusing on interactive learning and active participation. It was implemented using different teaching methods and media such as short lectures, group discussion, in addition to different audiovisual materials as pamphlets, pictures, posters and video to facilitate the teaching of each topic.

\section{Evaluation phase}

The program outcome was evaluated using Tool II and III, immediately after program implementation, before one day from discharge. The patients' theoretical knowledge regarding cerebrovascular stroke recurrent was evaluated by using Tool II. But the studied patients' level of self-efficacy was measured using Tool III. The second evaluation was conducted after two months from the educational program implementation. The researcher informed the studied patients that came for evaluation regarding the effectiveness of the program and interviewed them using the questionnaires at the time of clinical visit. Follow up was done. All these were done through previously registered mobile call under the researcher cost by using Tool II and Tool III.

\section{Ethical considerations}

Informed consent was obtained from participant after explaining the purposes of the study. No harmful methodology was used with participant; they had right to withdraw from the study at any time.

\section{Statistics Analysis}

Handling and analysis of data: The raw data were coded and entered into SPSS system files (SPSS package version 19). Analysis and interpretation of data were conducted. The following statistical measures were used:

Descriptive statistics was done including frequency, distribution, mean, and standard deviation. Univariate analyses, including Student $t$-test, ANOVA test, Mann Whitney test and Kruskal Wallis test were used to test the significance of results of quantitative variables. Mac Nemar test of significance, Spearman's rank correlation coefficient or Spearman's rho and A chi-squared test was also done. Significant of results was done at $P \leq 0.05$. 


\section{RESULTS}

\section{Table 1: Demographic characteristics}

\begin{tabular}{|c|c|c|}
\hline \multirow{2}{*}{ Demographic characteristics } & \multicolumn{2}{|c|}{$\begin{array}{l}\text { The Studied patients } \\
(\mathrm{n}=84)\end{array}$} \\
\hline & no. & $\%$ \\
\hline \multicolumn{3}{|l|}{ Age (years) } \\
\hline \multirow{3}{*}{$\begin{array}{l}-20- \\
. \quad 56-\end{array}$} & 16 & 19.04 \\
\hline & 68 & 80.96 \\
\hline & \multicolumn{2}{|c|}{$\begin{array}{c}\text { Mean } \pm \text { SD } \\
50 \pm 9\end{array}$} \\
\hline Gender & & \\
\hline - Male & 50 & 59.5 \\
\hline - Female & 34 & 40.5 \\
\hline Employment & & \\
\hline - $\quad$ Not working & 44 & 52.4 \\
\hline - Work & 40 & 47.6 \\
\hline Marital status & & \\
\hline - Single & 4 & 4.8 \\
\hline - $\quad$ Married & 69 & 82.1 \\
\hline - Divorced/widow & 11 & 13.1 \\
\hline Educational level & & \\
\hline - $\quad$ Illiterate & 46 & 54.8 \\
\hline - $\quad$ Can read and write & 38 & 45.2 \\
\hline
\end{tabular}

Table 1 revealed that more aged above 56 years (80.96), male $(59.5 \%)$ and a mean age of 50 years $(\mathrm{SD}=9)$, ranging from 50 to 59 years. Most of the participants were not worker $(52.9 \%)$, more married $(82.1 \%)$ and lived in urban areas $(100 \%)$. In addition, $(54.8 \%)$ were illiterate.

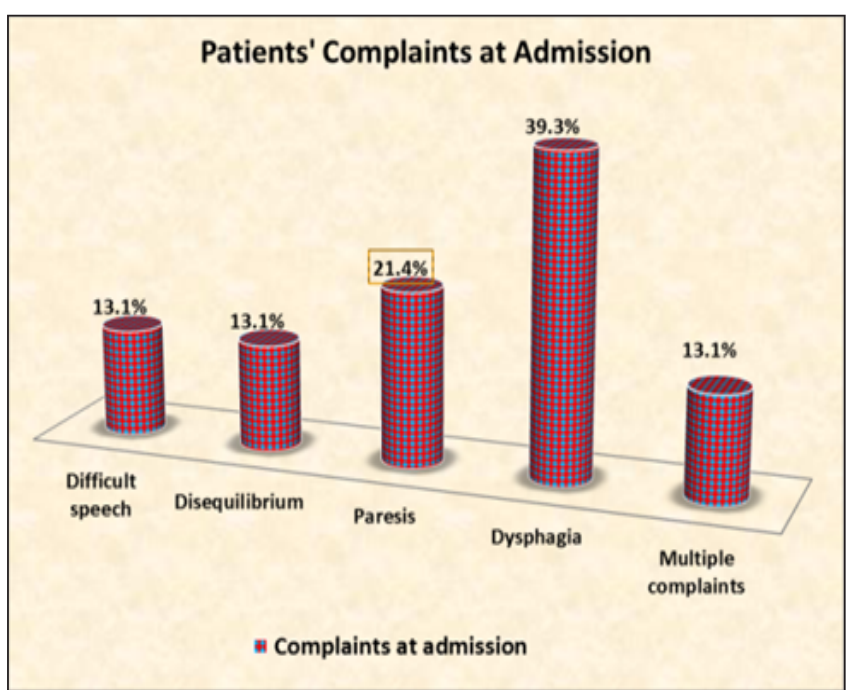

Figure 1: Distribution of patients' complaints at admission among the studied patients. $(n=84)$

Figure 1 portrayed that $39.3 \%$ of the studied patients had dysphagia at admission, while $21.4 \%$ of them had parenthesis.

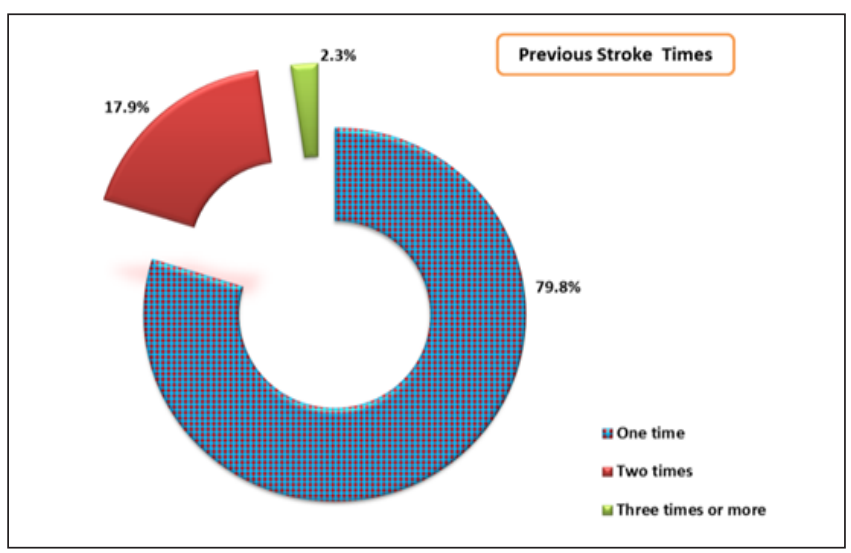

Figure 2: Distribution of previous stroke times among the studied patients $(n=84)$

Figure 2 illustrated that $79.8 \%$ of the studied patients had a onetime history of cerebrovascular stroke recurrent, $17.9 \%$ had two previous stroke times, while $2.3 \%$ of them had three times or more a past history of recurrent cerebrovascular stroke.

Table 2: Satisfactory level of knowledge among the studied patients at the study phases $(n=84)$

\begin{tabular}{|l|l|c|c|c|c|c|c|}
\hline \multirow{2}{*}{ Scores of Knowledge } & \multicolumn{2}{|c|}{ Before } & \multicolumn{2}{c|}{ After } & \multicolumn{2}{c|}{ Follow up } \\
\cline { 3 - 8 } & No. & $\%$ & No. & $\%$ & No. & $\%$ \\
\hline $\begin{array}{l}\text { Definition \& } \\
\text { types }\end{array}$ & Satisfactory & 18 & 21.4 & 80 & 95.2 & 64 & 76.2 \\
\hline Risk factors & Satisfactory & 0 & 0.0 & 66 & 78.6 & 61 & 72.6 \\
\hline $\begin{array}{l}\text { Clinical } \\
\text { picture }\end{array}$ & Satisfactory & 5 & 6.0 & 67 & 79.8 & 66 & 78.6 \\
\hline $\begin{array}{l}\text { Management } \\
\text { diagnosis * } \\
\text { treatment) }\end{array}$ & Satisfactory & 10 & 11.9 & 76 & 90.5 & 67 & 79.8 \\
\hline
\end{tabular}

Table 2 Clarified that $21.4 \%$ had a satisfactory level regarding definition and types of stroke at pre phase, while $95.2 \%$ at post phase, as well as $6 \%$ had satisfactory level regarding clinical pictures at pre phase, while $78.6 \%$ at follow up.

Table 3: Correlation between the studied patient's stroke self-efficacy score at the study phases. $(n=84)$

\begin{tabular}{|c|c|c|c|c|c|c|}
\hline \multirow{2}{*}{ Self-Efficacy score } & Pre & Post & Follow up & \multirow{2}{*}{$\begin{array}{c}\text { Test } \\
\text { value• }\end{array}$} & \multirow[t]{2}{*}{$\begin{array}{c}P \text { - } \\
\text { value }\end{array}$} & \multirow{2}{*}{ Sig. } \\
\hline & No. $=84$ & No. $=84$ & No. $=84$ & & & \\
\hline Mean \pm SD & $26.43 \pm 8.08$ & $23.98 \pm 7.54$ & $23.12 \pm 7.31$ & 8.680 & 0.003 & HS \\
\hline
\end{tabular}
highly significant (HS)

Table 3 presented that there was positive significant correlation between the studied patient's stroke selfefficacy score at the pre, post and follow up phase of the study. 


\section{DISCUSSION}

The findings of the present study revealed that more than half of the studied patients age was $>55$ years old. Supporting these findings, Jang \& Shin, (2019), stated that as recurrent cerebrovascular stroke' incidence is increasing, so it is important for these patients to adhere to their self-care performance. Contradictory to these findings, Dastjerdil et al., (2016), found that most of the patients were $<63$ years of age. At the researcher point of view; this is due to highly precipitating factors among this age group as physiological and psychological changes occur at this time.

The result of the present study revealed that the majority of the studied patients were male. This result agreed with Kim et al., (2013), who found the majority of the studied patients were male. At the researcher's point of view this is due to the fact that males are at more risk and they are busier in daily stressors, lack of knowledge and health care services to follow up. In contrast to this Salama \& Hammad, (2015), found more than three-quarter of the studied patients were female. At the researcher's point of view; this may be related to the burdens, medical history or/and other risky condition among females in this study settings.

The result of the present study revealed that more than half of the studied patients were not working. This result agreed with (Morsy et al., 2013), who found that the majority of the studied patients were not working. At the researcher's point of view; due to advance of age, and work culture among this this group of business population. In contradiction to these findings Cecily, (2016), found that more than the majority of studied patients were Coolie workers.

The result of the present study revealed that more than half of the studied patients were illiterate. This result agreed with Lee et al., (2014), who revealed that majority of the studied patients were unable to read and write. Contradictory with these findings another study (Mahmoud \& Elaziz, 2016), found that more than threequarter were able to read and write.

The result of the present study revealed that the studied patients had a satisfactory level of overall knowledge regarding recurrent cerebrovascular stroke (definition, causes and risk factors, types, clinical manifestation, diagnostic studies, treatment modalities, complication and causes of recurrent) at post and follow-up phase of program implementation. Agreed to these findings Lee et al., (2014), found that more than three-quarter of the studied patients had taken effective educational program regarding their knowledge about disease.

Also Denny et al., (2017), found that the majority had significant improvement of knowledge regarding their disease. At the researcher point of view, measures should be taken to motivate the patient to avoid recurrence of cerebrovascular stroke. This is possible through effective educational skills, adequate suitable supplies, available lecture rooms and readiness of all associated factors, as well as support. Martinez et al., (2016), found that increased perception of barriers relating to general medical knowledge, medication adherence, and healthcare access, have decreased stroke knowledge (including knowledge of acute stroke therapy), and they have higher reliance on "powerful others" for control of their health.

The result of the present study revealed that there was no significant relation between the studied patients' level of knowledge score and demographic variables (age, gender, employment, marital status and educational level) at pre, post and follow-up phase. Contradicted with these finding Cecily, (2016), found that variables like age, sex, marital status, educational status, occupation, monthly family income, duration of illness and duration of treatment had significant association with the level of knowledge regarding stroke.

The result of the present study revealed that there was a significant correlation between the studied patients' level of knowledge score at pre post phase and post follow-up phase. This was in line with another study (Denny et al., 2017), who found a significant correlation between the studied patients' level of knowledge at the phases of the study.

The result of the present study revealed that there is no significant correlation between pre, post and followup phase of the study regarding stroke self-efficacy scale of the studied patients. These findings were not supported by the findings of Lo, (2016), who found that a statistically significant correlation between stroke self-efficacy scale score at pre and post phase. Also, Appalasamy et al., (2018), found that a significant correlation between pre and follow-up phase of the study regarding stroke self-efficacy scale of the studied patients.

The result of the present study revealed that there is significant correlation between total adherence scores 
and total self-efficacy score at post phase. Cheiloudaki \& Alexopoulos, (2019) supported these findings showed significant correlation between adherance with therapies and their total self-efficacy score at post phase. Wolf et al., (2017), also found that there is a significant correlation between their adherence with therapies and stroke self-efficacy score. At the researcher point of view this is due to direct impact between these two variables among the studied patients.

The result of the present study revealed that there is significant relation with demographic characteristics as age, gender at pre phase and stroke self-efficacy score and marital status at post phase. Agreed with these findings Denny et al., (2017), detected that there was a statistically significant relation between social data as age, gender at pre phase and stroke self-efficacy score, also marital status at post phase. Pompey et al., (2017), found a positive correlation between demographic characteristic as age at pre phase of the study. This was also supported by Boden-Albala et al., (2019), who agree with these findings and detect a significant relation among the studied patients' demographic characteristics as age, gender at pre phase and stroke self-efficacy score, also marital status at post and follow-up phase.

\section{CONCLUSION}

In the light of the study findings, all of the studied patients had an improvement with satisfactory level of knowledge at the study phases. There was positive significant correlation between the studied patient's stroke self-efficacy score at the study phases.

\section{RECOMMENDATIONS}

Based upon findings of the current study, the followings are recommended:

- Establishing recurrent cerebrovascular stroke's counseling, specialized professional teams to provide knowledge and method of adherence with therapies to prevent recurrent cerebrovascular stroke.

- Emphasis must be given to centralized specialized units in the hospital concerns with education of the patients to modify their lifestyle "weight, diet, exercise, smoking, medication abuse, family relations, etc." This is effective to eradicate false habits and to ensure the importance of adherence.

- Submission of educational videos, handouts, posters, booklet, and brochure concerned with recurrent cerebrovascular stroke and its associated therapies can also be done.

- Periodical updating of the knowledge, the importance of adherence, methods to get rid of the factors affecting adherence and survey of the population, especially those who had a previous history of stroke

- Further studies and replication of this study on a larger probability sample selected from different geographical areas in Egypt is recommended to obtain more generalizable data.

\section{REFERENCES}

Abd-Allah, F., Khedr, E., Oraby, M.I., Bedair, A.S., Georgy, S.S. \& Moustafa, R.R. (2018). Stroke burden in Egypt: data from five epidemiological studies. International Journal of Neuroscience, 128(8), pp 765-771.

Appalasamy, J.R., Tha, K.K., Quek, K.F., Ramaiah, S.S., Joseph, J.P. \& Zain, A.Z.M. (2018). The effectiveness of culturally tailored video narratives on medication understanding and use self-efficacy among stroke patients: A randomized controlled trial study protocol. Medicine, 97(22), e10876.

Benjamin, E.J., Virani, S.S., Callaway, C.W., Chamberlain, A.M., Chang, A.R., Cheng, S., Chiuve, S.E., Cushman, M., Delling, F.N., Deo, R., de Ferranti, S.D., Ferguson, J.F., Fornage, M., Gillespie, C., Isasi, C.R., Jiménez, M.C., Jordan, L.C., Judd, S.E., Lackland, D., Lichtman, J.H., Lisabeth, L., Liu, S., Longenecker, C.T., Lutsey, P.L., Mackey, J.S., Matchar, D.B., Matsushita, K., Mussolino, M.E., Nasir, K., O'Flaherty, M., Palaniappan, L.P., Pandey, A., Pandey, D.K., Reeves, M.J., Ritchey, M.D., Rodriguez, C.J., Roth, G.A., Rosamond, W.D., Sampson, U.K.A., Satou, G.M., Shah, S.H., Spartano, N.L., Tirschwell, D.L., Tsao, C.W., Voeks, J.H., Willey, J.Z., Wilkins, J.T., Wu, J.H., Alger, H.M., Wong, S.S. \& Muntner, P.; American Heart Association Council on Epidemiology and Prevention Statistics Committee and Stroke Statistics Subcommittee (2018). Heart disease and stroke statistics - 2018 update: a report from the American Heart Association. Circulation, 137(12), e67-e492. 
Bland, M. \& Altman, G. (1997). Statistics notes: Cronbach's alpha. British Medical Journal, 31(4), pp. 572-574.

Boden-Albala, B., Goldmann, E., Parikh, N. S., Carman, H., Roberts, E.T., Lord, A.S., Torrico, V., Appleton, N., Birkemeier, J., Parides, M. \& Quarles, L. (2019). Efficacy of a discharge educational strategy vs standard discharge care on reduction of vascular risk in patients with stroke and transient ischemic attack: the DESERVE randomized clinical trial. JAMA Neurology, 76(1), pp 20-27.

Cabral, N., Muller, M., Franco, S., Longo, A., Moro, C. \& Nagel,V. (2015). Three-year survival and recurrence after firstever stroke: the Joinville stroke registry. BMC Neurology Journal, 15(70), pp.2-8.

Cecily, H.S.J. (2016). Knowledge on Prevention of Cerebro Vascular Accident among Patients with Diabetes and Hypertension in India. IJSR International Journal of Science and Research (IJSR), 5(3), pp 1401-1404.

Cheiloudaki, E. \& Alexopoulos, E.C. (2019). Adherence to Treatment in Stroke Patients. International Journal of Environmental Research and Public Health, 16(2), pii: 196.

Dastjerdil, V.N., Rafiee, Z., Mohammadi, A. \& Pahlavan zadeh,Z. (2016). The impact of self-efficacy on self-care ability of patients with stroke: a clinical trial study. Faculty of Nursing, Isfahan University of Medical Sciences, Isfahan, Iran, pp 51-57.

Denny M.C., Vahidy, F., Vu K.Y., Sharrief A.Z. \& Savitz, S.I. (2017). Video-based educational intervention associated with improved stroke literacy, self-efficacy, and patient satisfaction. PLoS One, 12(3): e0171952.

Elbqry, M.G., Sherif, W.I., Mahdy, N.E., Gaballah, S.H. \& Altantawy, A.M. (2019). Effect of Educational Program on knowledge, Adherence and Self-Efficacy among Patients with Recurrent Cerebrovascular Stroke. Journal of Nursing and Health Science, 8(4), pp 42-51.

Hinkle, L., Becker, J., Kim, S., Choi-Kwon, S., Saban, L., McNair, N. \& Mead, E. (2017). Post stroke fatigue: emerging evidence and approaches to management: a scientific statement for healthcare professionals from the American Heart Association. Stroke, 48 (7), pp 159-170.

Jang, D.E. \& Shin, J.H. (2019). Self-Care Performance of Middle-Aged Stroke Patients in Korea. Clinical nursing research, 28(3), pp 263-279.

Jones, F., Partridge, C. \& Reid, F. (2008). The stroke self-efficacy question-naire: Measuring individual confidence in functional performance after stroke. Journal of Clinical Nursing, 17(7B), pp 244-252

Kamal, A.K., Shaikh, Q., Pasha, O., Azam, I., Islam, M., Memon, A.A., Rehman H., Akram M.A., Affan, M., Nazir, S., Aziz, S., Jan, M., Andani, A., Muqeet, A., Ahmed, B. \& Khoja, S. (2015). A randomized controlled behavioral intervention trial to improve medication adherence in adult stroke patients with prescription tailored Short Messaging Service (SMS)-SMS4Stroke study. BMC Neurology, 15(1), 2095.

Khedr, E.M., Fawi, G., Abdela, M., Mohammed, T.A., Ahmed, M.A., El-Fetoh, N.A. \& Zaki, A.F. (2014). Prevalence of ischemic and hemorrhagic strokes in Qena Governorate, Egypt: community-based study. Journal of Stroke and Cerebrovascular Diseases, 23(7), pp 1843-1848.

Kim, J., Bushnell, C.D., Lee, H.S. \& Han, S.W. (2018). Effect of Adherence to Antihypertensive Medication on the LongTerm Outcome After Hemorrhagic Stroke in Korea. Hypertension, 72(2), pp 391-398.

Kim, J.I., Lee, S. \& Kim, J.H. (2013). Effects of a web-based stroke education program on recurrence prevention behaviors among stroke patients: a pilot study. Health Education Research Health Education Research, 28(3), pp 488-501.

Lau, G.K.K., Pendlebury, S.T. \& Rothwell, P.M. (2018). Transient Ischemic Attack and Stroke: Diagnosis, Investigation and Treatment. $2^{\text {nd }}$ edition, Cambridge, UK: Cambridge University Press.

Lee, R., Ham, K., Lee, W., Cho, I., Oh, S. \& Rha, H. (2014). Knowledge, health-promoting behaviors, and biological risks of recurrent stroke among stroke patients in Korea. Japan Journal of Nursing Science, 11(2), pp 112-120. 
Lewis, L., Bucher, L., Heitkemper, M., Harding, M., Kwong, J. \& Roberts, D. (2016). Medical-Surgical Nursing-EBook: Assessment and Management of Clinical Problems, Single Volume: Elsevier Health Sciences $10^{\text {th }}$ ed, pp 20102018.

Lo, H.S. (2016). Effectiveness of a self-efficacy enhancing stroke self-management program on promoting recovery of community-dwelling stroke survivors. Australia: Queensland University of Technology.

Mahdy, N.E., Mohamed, Y.M. \& Nagm, L.M.A. (2016). Positioning and Early Mobilization: Effect of Educational Guidelines on Nurses' performance and Stroke Patients' Outcome. Journal of American Science, 12(8), pp 131-146.

Mahmoud, S. \& Elaziz, N.A.A. (20160. Impact of stroke on life satisfaction and psychological adjustment among stroke patients during rehabilitation. Life Science Journal, 13(3), pp 7-17.

Martinez, M., Prabhakar, N., Drake, K., Coull, B., Chong, J., Ritter, L. \& Kidwell, C. (2016). Identification of barriers to stroke awareness and risk factor management unique to Hispanics. International Journal of Environmental Research and Public Health, 13(1): 23.

Martino, M., Alagna, M., Cappai, G. \& Mataloni, F. (2016). Adherence to evidence-based drug therapies after myocardial infarction: is geographic variation related to hospital of discharge or primary care providers? A crossclassified multilevel design. British Medical Journal, 6(4), pp 2-9.

Morsy, W.Y.M., Elfeky, H.A. \& Ahmed, R.A. (2013). Cerebrovascular Stroke Recurrence among Critically Ill Patients at a Selected University Hospital in Egypt. Journal of Biology, Agriculture and Healthcare, 3(13), pp 22-33.

Pendlebury, S., Rothwell, P. \& Lau, G., (2018). Transient ischemic attack and stroke : diagnosis, investigation and treatment. British Medical Journal, 21(16), pp 20-30

Pompey, C.S., Muensri, B. \& Kritpracha, C. (2017). Self-Efficacy to Perform Activities of Daily Living Predicts Independence in Activities of Daily Living in Subacute Stroke Patients. GSTF Journal of Nursing and Health Care $(J N H C), 4(1)$.

Salama, H. \& Hammad, E. (2015). Risk Association between TNF-alpha-308 G> A and IL-6-174 G/C Polymorphisms and Recurrent Transient Ischemic Attacks. The Egyptian Journal of Immunology, 22(2), pp 49-56.

Urden, L.D., Stacy, K.M. \& Lough, M.E. (2017). Critical Care Nursing-E-Book: Diagnosis and Management, Elsevier Health Sciences.

Wolf, T.J., Spiers, M.J., Doherty, M. \& Leary, E.V. (2017). The effect of self-management education following mild stroke: An exploratory randomized controlled trial. Topics in Stroke Rehabilitation, 24(5), pp 345-352.

World Heart Organization (2019). Stroke, Cerebrovascular Accident. Retrieved from: (10/6/2019- 6.00 pm) from http://www.emro.who.int/health-topics/stroke-cerebrovascular-accident/index.html 